\title{
Balance and healthy aging: a close relationship
}

Sara Almeida, ${ }^{1-2}$ Cátia Paixão, ${ }^{1-2}$ Alda Marques ${ }^{1-2}$

\section{RESUMO}

Objectives: This study explored the: i) correlations between the Balance Evaluation Systems Test (BESTest) and its short-versions (Mini-BESTest and Brief-BESTest), with functional ability, gait speed, physical activity, and health-related quality of life; ii) ability of the Five Times Sit to Stand (5STS), 10 Meter Walk Test (10MWT), Brief Physical Activity Assessment Tool (BPAAT) and World Health Organization Quality of Life-Bref (WHOQoL-Bref) to identify the prior history of falls in community-dwelling older people.

Methods: An exploratory cross-sectional study was conducted with healthy older people living in the community. Balance (BESTest and its short versions), functional ability (5STS), gait speed (10MWT), physical activity (BPAAT), and health-related quality of life (WHOQoL-Bref) were assessed. Spearman correlation coefficient and receiver operating characteristics analysis were calculated.

Results: One hundred and eighteen individuals (76[69-83.3] years; $n=79,66.9 \%$ female) participated in this study. Correlations between balance and functional ability $(-0.61<r<-0.51, p<0.001)$, gait speed $(0.69<r<0.78, p<0.001)$, physical activity $(0.39$ $<r<0.42, p<0.001)$ and health-related quality of life $(0.28<r<0.57, p \leq 0.002)$ were identified. The following cutoff points to differentiate between prior history of falls were established: 80.5 points for the BESTest, 16.5 points for the Mini-BESTest and 12.5 points for the Brief-BESTest, $13.5 \mathrm{~s}$ for the $5 \mathrm{STS}, 1.2 \mathrm{~m} / \mathrm{s}$ for the $10 \mathrm{MWT}, 1.5$ points for the BPAAT and 14.5/66; 14.5/66; 14/62.5; 15.5/72 points for domains I, II, III and IV, respectively, of the WHOQoL-Bref 0-20/100.

Conclusion: The BESTest and its short versions correlated with functional ability, gait speed, physical activity, and health-related quality of life in older people. These outcomes can differentiate prior history of falls in community-dwelling older people.

Keywords: Community-dwelling older people; Falls; Functional ability; Health-related quality of life; Self-reported physical activity.

\section{INTRODUCTION}

$\mathrm{H}$ ealthy aging is defined "as the process of developing and maintaining the functional ability that allows well-being in older people". ${ }^{1}$ Balance plays an important role in functional ability and falls and, consequently, in the daily life of older people, ${ }^{1-3}$ resulting in a potential impact on healthy aging. ${ }^{3-4}$ Furthermore, associations between balance and recognized predictors of healthy aging (e.g., functional ability, ${ }^{5}$ gait speed, ${ }^{6}$ self-reported physical activity $[\mathrm{PA}]^{7}$ and health-related quality of life $[\mathrm{HRQoL}])^{8}$ have been reported.

Balance may be assessed in older people through a number of outcome tools, such as the Berg Balance Scale (BBS), the Timed Up and Go test (TUG), and the

1. Lab3R - Respiratory Research and Rehabilitation Laboratory (Lab3R), School of Health Sciences, University of Aveiro, Aveiro, Portugal.

2. Institute for Biomedicine (iBiMED), University of Aveiro, Aveiro, Portugal
Functional Reach Test. ${ }^{9}$ However, most of these balance tools present ceiling effects in older people ${ }^{10}$ and none identify the different balance systems. Thus, a clinical comprehensive tool of balance, the Balance Evaluation Systems Test (BESTest), and its short versions (e.g., Mini-BESTest and Brief-BESTest), were developed to overcome these limitations. ${ }^{11-13}$ BESTest and its short versions have been providing valuable information to tailor interventions for improving balance in healthy older people. ${ }^{2}$ However, the correlation between the BESTest and its short versions with tools of healthy aging in community-dwelling older people remains unknown.

Additionally, falls affect healthy aging, as it is known that these events result in loss of independence, disability, social isolation, institutionalization, morbidity, and mortality. ${ }^{3}$ Balance tools have been shown to be able to identify fall status in older people, ${ }^{4,14}$ however the 
etiology of falls is multifactorial. ${ }^{3,15}$ Thus, functional ability, gait speed, self-reported PA, and HRQoL may also play an important role in identifying people at risk of falling who will benefit from a more comprehensive assessment of balance and, if needed, a personalized balance intervention. The Five Times Sit to Stand test (5STS), the 10 MeterWalk Test (10MWT), and the World Health Organization Quality of Life-Bref (WHOQoLBref) have been recognized as tools able to identify healthy aging ${ }^{14,16-17}$ and falls in older people. ${ }^{18-20}$ The Brief PA assessment tool (BPAAT) has been poorly studied, however, PA is strongly associated with healthy aging and falls. ${ }^{21}$ Nevertheless, research on the ability of the 5STS, 10MWT, WHOQoL-Bref, and BPAAT tools to identify the history of falls in older people is scarce and it is important to be conducted since those who have fallen are at higher risk to fall again. ${ }^{22}$

Therefore, this study aimed to explore the correlation between BESTest and its short versions, and functional ability, gait speed, self-reported PA and HRQoL; and to establish the ability of 5STS, 10MWT, BPAAT, and WHOQoL-Bref to identify the history of falls in community-dwelling older people. We hypothesized that higher balance scores will be positive and strongly correlated with better performances in functional ability, gait speed, self-reported PA, and HRQoL and that these tools will be able to identify a history of falls in community-dwelling older people.

\section{METHODS}

\section{Study design and ethics}

An exploratory cross-sectional study in communitydwelling older people was conducted. Ethical approval was first obtained (238/10-2014) followed by informed consent.

\section{Participants}

Community-dwelling older people were recruited from six day-care centers, two gymnasiums, and one senior university. The manager of each institution identified and explained the study to eligible people. A meeting was scheduled with interested people and the researcher provided further information about the study.

Community-dwelling older people were eligible if they: were $\geq 60$ years old; ${ }^{23}$ understood the aims of the study; were able to express their opinions; demon- strated coherent discourse and spatiotemporal orientation, and voluntarily accepted to participate. Exclusion criteria involved any condition that could potentially influence scores on balance measurements, such as: hospitalization in the previous month; a history of dizziness or fainting; medication that could cause dizziness or impaired balance; depressive disorders; signs of cognitive impairment or psychiatric symptoms; significant musculoskeletal, neurological or cardiorespiratory disorders; the need of physical assistance to walk; and/or signs of substances abuses.

\section{Data collection}

Sociodemographic (age and gender) and anthropometric (height, weight, body mass index [BMI], and percentage of fat-free mass [FFM]) data were first collected, through a structured questionnaire based on the International Classification of Functioning, Disability and Health (ICF-checklist). BMI (weight/height ${ }^{2}$ ) and FFM (\%) were assessed with a bioimpedance equipment (Omron body fat monitor BF306). The self-reported number of falls was assessed using two standardized questions (1. «Have you had any fall in the last 12 months? / Teve alguma queda nos últimos 12 meses?» and, if yes, 2. «How many times did you fall down in the last 12 months? / Quantas quedas teve nos últimos 12 meses?»), after presenting to each participant a clear definition of falls ("an event when you find yourself unintentionally on the ground, floor or lower level"). ${ }^{3}$

Then performance-based tests (BESTest, 5STS, and 10MWT) were performed. First, tests' instructions were read by one researcher while a second researcher demonstrated the task to the participant. One researcher provided supervision to ensure the participant's safety during physical tests. All tests were assessed by the same assessor to ensure data reliability.

The balance was assessed with the BESTest and its short-versions. The BESTest is a clinical comprehensive balance assessment tool, with 36 items and categorized into six balance systems: biomechanical constraints, stability limits/verticality, transitions/anticipatory postural adjustments, reactive postural control, sensory orientation, and stability in gait. ${ }^{12}$ Each task is scored on an ordinal scale from zero(severe impairment) to three (no impairment). ${ }^{12-13}$ The total score is 
108 points, with higher scores indicating better balance performance. ${ }^{12-13}$ BESTest takes between 20-60 minutes to administer, ${ }^{12-13}$ thus its use may not be doable in clinical practice. Therefore, a short version, Mini-BESTest, has been proposed to reduce the assessment time. ${ }^{11}$

The Mini-BESTest takes 10-15 minutes to apply and includes 14 items from the original BESTest, based in four balance systems: anticipatory postural adjustments, reactive postural responses, sensory orientation, and stability in gait. ${ }^{11}$ The Mini-BESTest total score is 32 points and each task is scored on a 3-point scale (zero to two), with higher scores indicating better performance. ${ }^{11}$ Nevertheless, as the Mini-BESTest does not identify the six balance systems of the original BESTest, the Brief-BESTest has been proposed.

The Brief-BESTest takes only 10 minutes to be applied and consists of six items of the original BESTest. ${ }^{13}$ Each task is scored on a four-point scale (zero to three), with a total score of 24 points, with higher scores indicating better balance performance. ${ }^{13}$

Functional ability was assessed with the $5 \mathrm{STS},{ }^{19}$ gait speed with the $10 \mathrm{MWT},{ }^{24} \mathrm{PA}$ with the BPAAT, ${ }^{25}$ and the HRQoL with WHOQoL-Bref. ${ }^{16,26}$

The 5STS consists of standing up and sitting down from a straight-backed armless chair with a hard seat stabilized against a wall for five repetitions. ${ }^{19}$ Longer time (seconds) to perform the test indicates worst functional ability performance. ${ }^{19}$

The 10MWT consists of walking 10 meters distance at a comfortable gait speed, whilst the velocity achieved during the intermediate six meters is recorded.$^{24}$ Higher scores $(\mathrm{m} / \mathrm{s})$ indicate worst gait speed performance. ${ }^{24}$

The BPAAT consists of two questions (1. «How many times a week do you usually do 20 minutes or more of vigorous-intensity PA that makes you sweat or puff and pant? (e.g., heavy lifting, digging, jogging, aerobics, or fast bicycling)» [3 or more times a week, 1 to 2 times a week, none] / «Quantas vezes por semana, costuma realizar 20 minutos de atividade física intensa que o faz suar ou ficar ofegante? (e.g., jogging, levantamento de grandes pesos, cavar, aeróbica ou andar de bicicleta a um ritmo rápido)» [3 ou mais vezes por semana, 1 a 2 vezes por semana, nenhuma]; 2. «How many times a week do you usually do 30 minutes or more of moderate-intensity $\mathrm{PA}$ or walking that increases your heart rate or makes you breathe harder than normal? (e.g., carrying light loads, bicycling at a regular pace, or doubles tennis)» [5 or more times a week, 3-4 times a week, 1-2 times a week, none] / «Quantas vezes por semana, costuma realizar 30 minutos de atividade física moderada ou caminhada que aumenta a sua frequência cardíaca ou o faz respirar com mais dificuldade que o normal? (e.g., cortar a relva, transportar cargas leves, andar de bicicleta a um ritmo regular, ou jogar ténis em duplas)» [5 ou mais vezes por semana, 3 a 4 vezes por semana, 1 a 2 vezes por semana, nenhuma]) assessing the frequency and duration of intense and moderate PA, undertaken in a usual week. ${ }^{25,27} \mathrm{~A}$ total score was calculated (range zero to eight), in which higher scores correspond to higher PA levels (scores $<4$ indicate that the person is insufficiently active and scores $\geq 4$ indicate that the person is sufficiently active).$^{25}$

The WHOQoL-Bref is a short version of the original WHOQoL and assesses four domains of quality of life: I-Physical, II-Psychological, III-Social relationships, and IV-Environment. ${ }^{26}$ This scale is composed of 26 questions, scored on a Likert scale from one to five, with higher scores indicating better quality of life. ${ }^{26}$

\section{Data analysis}

Statistical analyses were performed in IBM SPSS 24.0 (IBM Corp., Armonk, NY) and GraphPad Prism 5.01 (GraphPad Software, San Diego, CA). The level of significance was set at 0.05 .

Descriptive statistics were used to characterize the sample. Participants were classified into two groups: non-fallers (reported history of zero or one fall) and multiple fallers (reported history of $\geq 2$ falls). The normality of data distribution was tested with the Kolmogorov-Smirnov test and z-test with the skewness and Kurtosis. ${ }^{28}$ Comparisons between groups were performed with Mann-Whitney-U tests since most variables were not normally distributed. If significant differences in the performance of the tests were found, effect sizes (ES) were computed with Cohen's $d$ (small $d$ $\geq 0.2$, medium $d \geq 0.5$ or large $d \geq 0.8$ effect). ${ }^{28}$ The skewness of the distribution of scores was assessed for each tool to verify the occurrence of floor and ceiling effects (substantial floor effect: skewness $>1$; substantial ceiling effect: skewness $<-1){ }^{28}$

Correlations were assessed using Spearman rank correlation and interpreted as negligible $(0-0.30)$, low $(0.30$ 


\begin{tabular}{|c|c|c|c|c|}
\hline Characteristics & Overall $(n=118)$ & $\begin{array}{l}\text { Non-fallers }(0-1) \\
(n=98)\end{array}$ & $\begin{array}{c}\text { Multiple fallers } \\
\text { (2 or more) }(n=20)\end{array}$ & p-value \\
\hline Age (years) & $76[69-83.3]$ & $74[68-82]$ & $80.5[71.5-87.5]$ & 0.063 \\
\hline Gender (female $n, \%$ ) & $79,66.9 \%$ & $63,64.3 \%$ & $16,80 \%$ & 0.203 \\
\hline FFM (\%) & $34.9 \pm 7.3$ & $34.7 \pm 7.5$ & $35.9 \pm 6.6$ & 0.514 \\
\hline BMI $\left(\mathrm{kg} / \mathrm{m}^{2}\right)$ & $26.2[24-29]$ & $26.2[24-29.3]$ & $27.1[23.8-28.5]$ & 0.917 \\
\hline \multicolumn{5}{|l|}{ Tools } \\
\hline BESTest (points) & $87.5[68.8-94.4]$ & $87.9[74.9-95.4]$ & $61.7[53.6-85.9]$ & $0.001^{*}$ \\
\hline Mini-BESTest (points) & $22.5[14-29]$ & $25[17-30]$ & $7.5[5-19]$ & $<0.001^{*}$ \\
\hline Brief-BESTest (points) & 16 [9 - 20.3] & $17[12-21]$ & $6.5[3-11.8]$ & $<0.001^{*}$ \\
\hline 5STS (s) & $12.1[9.1-16.5]$ & $11.5[8.9-15.7]$ & $17.5[13-25.3]$ & $0.002^{*}$ \\
\hline 10MWT (m/s) & $1.3[1-2.1]$ & $1.5[1.1-2.2]$ & $0.9[0.6-1.2]$ & $0.001^{*}$ \\
\hline BPAAT & $1.5[0-8]$ & $2[0-8]$ & $0[0-3]$ & $<0.001^{*}$ \\
\hline Sufficiently active score $\geq 4(n, \%)$ & $31,26.3 \%$ & $67,68.4 \%$ & - & - \\
\hline Insufficiently active score $0-3(n, \%)$ & $87,73.7 \%$ & $31,31.6 \%$ & $20,100 \%$ & - \\
\hline \multicolumn{5}{|l|}{ WHOQoL-Bref 0-20 score (points) } \\
\hline I- Physical health & $15[13-17]$ & $15.2[13-17]$ & $13[11-14]$ & $<0.001^{*}$ \\
\hline II - Psychological & $15[13-17]$ & $15[13-17]$ & $13[12-14.8]$ & $<0.001^{*}$ \\
\hline III - Social relationships & $15[13-16]$ & $15[13-16]$ & $13[11-15.8]$ & $0.019 *$ \\
\hline IV - Environment & $16[14-17]$ & $16[15-17]$ & $14[13-16]$ & $0.002^{*}$ \\
\hline \multicolumn{5}{|l|}{ WHOQoL-Bref 0-100 score (points) } \\
\hline I- Physical health & $69[56-81]$ & $69[56-81]$ & $56[44-63]$ & $<0.001^{*}$ \\
\hline II - Psychological & $69[56-81]$ & $69[56-81]$ & $56[50-67.5]$ & $<0.001^{*}$ \\
\hline III - Social relationships & $69[56-75]$ & $69[56-75]$ & $56[44-73.5]$ & 0.019* \\
\hline IV - Environment & $75[63-81]$ & $75[69-81]$ & $63[56-75]$ & $0.002 *$ \\
\hline
\end{tabular}

Note: values are presented in median [interquartile range] and mean \pm standard deviation unless otherwise stated.

Abbreviations: 5STS = Five Times Sit to Stand test; 10MWT = 10 Meter Walk Test; BESTest = Balance Evaluation Systems Test; BMI = Body Mass Index; BPAAT $=$ Brief Physical Activity Assessment Tool; FFM = Free-fat Mass Index; WHOQoL-Bref $=$ World Health Organization Quality of Life-Bref. ${ }^{*} p<0.05$ significance.

- 0.50), moderate $(0.50-0.70)$, high $(0.70-0.90)$ and very high $(0.90-1){ }^{28}$

Receiver operating characteristics (ROC) analysis was used to assess the ability of the tools to significantly differentiate between a self-reported prior history of non-fallers and multiple fallers. The cutoff was chosen as the value which simultaneously maximized the sensitivity and specificity: (1-sensitivity $)^{2}+(1 \text {-specificity })^{2}$ for each tool. ${ }^{28}$ Area under the curves (AUC) and $95 \%$ confidence interval $(95 \% \mathrm{CI})$ interpretation was:
AUC $=0.5$ no discrimination; $0.7 \leq \mathrm{AUC}<0.8$ acceptable; $0.8 \leq$ AUC $<0.9$ excellent, and AUC $\geq 0.9$ outstanding discrimination..$^{28}$ The positive and negative likelihood ratios (LR+ and LR-) were computed. ${ }^{28}$

\section{RESULTS}

One hundred and eighteen community-dwelling older people (mean \pm standard deviation $76.2 \pm 8.9$; median [interquartile range] 76 [69-83.3] years old; $n=79$; $69.9 \%$ female) were enrolled in this study. On average 
TABLE 2. Correlations between Balance Evaluation Systems Test, Mini-Balance Evaluation System Test and Brief-Balance Evaluation Systems Test, and Five Times Sit to Stand Test, 10 Meter Walk Test, Brief Physical Activity Assessment Tool and World Health Organization Quality of Life Bref $(n=118)$

\begin{tabular}{|c|c|c|c|c|c|c|}
\hline Variables & BESTest & $P$ & Mini-BESTest & $P$ & Brief-BESTest & $P$ \\
\hline 5STS & -0.51 & $<0.001$ & -0.59 & $<0.001$ & -0.61 & $<0.001$ \\
\hline 10MWT & 0.69 & $<0.001$ & 0.78 & $<0.001$ & 0.77 & $<0.001$ \\
\hline BPAAT & 0.39 & $<0.001$ & 0.40 & $<0.001$ & 0.42 & $<0.001$ \\
\hline \multicolumn{7}{|c|}{ WHOQoL-Bref (0-20 and 0-100 scores) } \\
\hline I - Physical health & 0.46 & $<0.001$ & 0.53 & $<0.001$ & 0.57 & $<0.001$ \\
\hline II - Psychological & 0.47 & $<0.001$ & 0.53 & $<0.001$ & 0.52 & $<0.001$ \\
\hline III - Social relationships & 0.32 & 0.002 & 0.28 & $<0.001$ & 0.36 & 0.002 \\
\hline IV - Environment & 0.46 & $<0.001$ & 0.46 & $<0.001$ & 0.51 & $<0.001$ \\
\hline
\end{tabular}

Note: Spearman correlation coefficient are presented.

Abbreviations: 5 STS = Five Times Sit to Stand Test; 10MWT = 10 Meter Walk Test; BESTest = Balance Evaluation Systems Test; BPAAT = Brief Physical Activity Assessment Tool; WHOQoL-Bref = World Health Organization Quality of Life Bref. $p<0.05$ significance.

participants were overweight (mean \pm standard deviation $26.8 \pm 4.2$ median [interquartile range] 26.2 [24-29] $\left.\mathrm{kg} / \mathrm{m}^{2}\right)$ and presented high FFM $(34.9 \pm 7.3 \%)$. Most individuals $(n=98 ; 83.1 \%)$ reported to have had zero or one fall, and $16.9 \%(n=20)$ reported to have had two or more falls in the previous year. Most participants were insufficiently active $(n=87 ; 73.7 \%)$. More than $1 / 3$ of nonfallers were insufficiently active $(n=31 ; 31.6 \%)$ and multiple fallers were all insufficiently active $(n=20 ; 100 \%)$ (Table 1).

All tools were able to significantly differentiate between a self-reported prior history of non-fallers and multiple fallers (Table 1). Non-fallers performed significantly better at the BESTest (ES=0.87), Mini-BESTest (ES=1.15), Brief-BESTest (ES=1.11), 5STS ( $\mathrm{ES}=0.76$ ), 10MWT ( $\mathrm{ES}=0.81$ ), BPAAT ( $\mathrm{ES}=0.97$ ), andWHOQoL-Bref domains 0-20 $\left(\mathrm{ES}_{\mathrm{DOM}-\mathrm{I}}=1.12, \mathrm{ES}_{\mathrm{DOM}-\mathrm{II}}=1, \mathrm{ES}_{\mathrm{DOM}-\mathrm{III}}=0.43\right.$ and $\left.\mathrm{ES}_{\text {DoM - IV }}=0.90\right)$ and 0-100 $\left(\mathrm{ES}_{\mathrm{DOM}_{-1}}=1.14, \mathrm{ES}_{\mathrm{DOM}-}\right.$ ${ }_{\mathrm{II}}=0.81, \mathrm{ES}_{\mathrm{DOM}-\mathrm{III}}=0.62$ and $\mathrm{ES}_{\mathrm{DOM}-\mathrm{IV}}=0.87$ ) than multiple fallers.

The 5STS (skewness=1.31) and the BPAAT (skewness $=1$ ) presented lower floor effects than the 10MWT (skewness=1.62). The WHOQoL-Bref ${ }_{0-20 \& 0-100}$ presented ceiling effect, which was higher in domains II and III

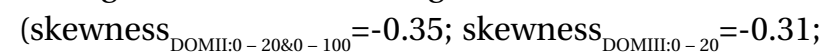
skewness $_{\text {DомाI:0 }-100}=-0.32$ ) than in domains I and IV (skewness $_{\text {DOMI:0-20 }}=-0.11$; skewness $_{\text {DOMI:0 - 100 }}=-0.10$; skewness $_{\text {DOMIV: } 0-20}=-0.08$; skewness $_{\text {DOMIV:0 }-100}=-0.07$ ).

The BESTest and its short versions showed positive correlations with the 10MWT, BPAAT and WHOQoLBref and negative correlations with the 5STS. Correlation values are presented in Table 2 . Scatterplots showing the correlations between BESTest, Mini-BESTest and Brief-BESTest and 5STS, 10MWT, BPAAT, and WHOQoL-Bref domains can be found in Figure S1 (supplementary material).

The AUC of the BESTest and its short versions, 5STS, 10MWT, BPAAT, and WHOQoL-Bref domains ranged between $0.65-0.79$, indicating that these tests were able to significantly discriminate between older people with and without a history of multiple falls. The short versions of the BESTest (Mini- [0.79] and Brief-BESTest [0.78]) and the WHOQoL-Bref domains I and II (AUC $=0.77$ for both), presented the higher AUCs. Table 3 shows the results of the ROC analysis.

To differentiate between a self-reported prior history of non-fallers and multiple fallers, the following cutoffs were identified: 80.5 points for BESTest, 16.5 points for Mini-BESTest, 12.5 points for Brief-BESTest, 13.5 seconds for $5 \mathrm{STS}, 1.2 \mathrm{~m} / \mathrm{s}$ for 10MWT, 1.5 points for BPAAT, $14.5 / 66$; 14.5/66; 15/62.5; 15.5/72 for domains I, II, III, and IV of the WHOQoL-Bref 0-20/0-100, 


\begin{tabular}{|c|c|c|c|c|c|c|}
\hline Tools & AUC (SEM) & $95 \% \mathrm{Cl}$ & $\begin{array}{l}\text { Cutoff } \\
\text { Point }\end{array}$ & $\begin{array}{c}\% \\
\text { Sensitivity }\end{array}$ & $\begin{array}{c}\% \\
\text { Specificity }\end{array}$ & $\begin{array}{l}\text { Positive/Negative } \\
\text { Likelihood Ratios }\end{array}$ \\
\hline BESTest (points) & $0.73(0.07)$ & $0.59-0.87$ & 80.5 & 75 & 68 & $2.34 / 0.37$ \\
\hline Mini-BESTest (points) & $0.79(0.06)$ & $0.68-0.91$ & 16.5 & 75 & 80 & $3.75 / 0.31$ \\
\hline Brief-BESTest (points) & $0.78(0.06)$ & $0.66-0.90$ & 12.5 & 80 & 75 & $3.20 / 0.27$ \\
\hline $5 S T S(s)$ & $0.72(0.07)$ & $0.59-0.86$ & 13.5 & 75 & 68 & $2.34 / 0.37$ \\
\hline 10MWT (m/s) & $0.74(0.06)$ & $0.61-0.86$ & 1.2 & 75 & 68 & $2.34 / 0.37$ \\
\hline BPAAT (number) & $0.65(0.06)$ & $0.53-0.76$ & 1.5 & 70 & 54 & $1.52 / 0.56$ \\
\hline \multicolumn{7}{|c|}{ WHOQoL-Bref 0-20 score (points) } \\
\hline I - Physical health & $0.77(0.05)$ & $0.67-0.88$ & 14.5 & 80 & 59 & $1.95 / 0.34$ \\
\hline II - Psychological & $0.76(0.05)$ & $0.66-0.86$ & 14.5 & 75 & 65 & $2.14 / 0.38$ \\
\hline III - Social relationships & $0.66(0.06)$ & $0.54-0.79$ & 14 & 55 & 65 & $1.57 / 0.69$ \\
\hline IV - Environment & $0.72(0.06)$ & $0.60-0.85$ & 15.5 & 65 & 64 & $1.81 / 0.55$ \\
\hline \multicolumn{7}{|c|}{ WHOQoL-Bref 0-100 score (points) } \\
\hline I - Physical health & $0.77(0.05)$ & $0.67-0.88$ & 66 & 80 & 59 & $1.95 / 0.34$ \\
\hline II - Psychological & $0.76(0.05)$ & $0.66-0.86$ & 66 & 75 & 65 & $2.14 / 0.38$ \\
\hline III - Social relationships & $0.66(0.06)$ & $0.54-0.79$ & 62.5 & 55 & 65 & $1.57 / 0.69$ \\
\hline IV - Environment & $0.72(0.06)$ & $0.60-0.85$ & 72 & 65 & 64 & $1.81 / 0.55$ \\
\hline
\end{tabular}

Abbreviations: BESTest $=$ Balance Evaluation Systems Test; 5STS = Five Times Sit to Stand test; 10MWT $=10$ Meter Walk Test; AUC $=$ Area Under the Curve; BPAAT = Brief Physical Activity Assessment Tool; $\mathrm{Cl}=$ Confidence interval; WHOQoL-Bref $=$ World Health Organization Quality of Life-Bref; $p<0.05$.

respectively. The cutoff points for all tools are presented in Table 3 and Figures 1 and 2.

\section{DISCUSSION}

According to the authors' best knowledge, this is the first study demonstrating that the BESTest and its short versions correlate significantly with functional ability, gait speed, self-reported PA, and HRQoL in community-dwelling older people and that these tools are able to differentiate between a self-reported prior history of non-fallers and multiple fallers in this population with sensitivities and specificities above $50 \%$.

Moderate to high correlations between balance and i) functional ability in people with multiple sclerosis, ${ }^{5}$ ii) gait speed in healthy people ( $>40$ years) ${ }^{6}$ iii) self-reported PA in older people, ${ }^{7}$ and iv) HRQoL in older peo$\mathrm{ple}^{8}$ have been previously demonstrated. However, the balance tools used in these studies (BBS, ${ }^{5-6} \mathrm{TUG}^{5}{ }^{5}$ and One Leg Stance test), ${ }^{7}$ are unable to assess balance comprehensively. The BESTest distinguishes itself from these other balance tools by allowing the identification of specific balance domains that are preserved or impaired hence, guiding personalized interventions. ${ }^{12}$ The correlations found between the BESTest and its short versions with the functional ability, gait speed, self-reported PA, and HRQoL strengthens the value of their use routinely, especially the short versions which presented similar or even higher correlations than the BESTest. This finding is of particular relevance for clinical practice since the short versions are simple, quicker and require less material to be applied. ${ }^{11,13}$

It is widely recognized that falls have a multifactorial etiology and numerous risk factors have been identified in community-dwelling older people, including 


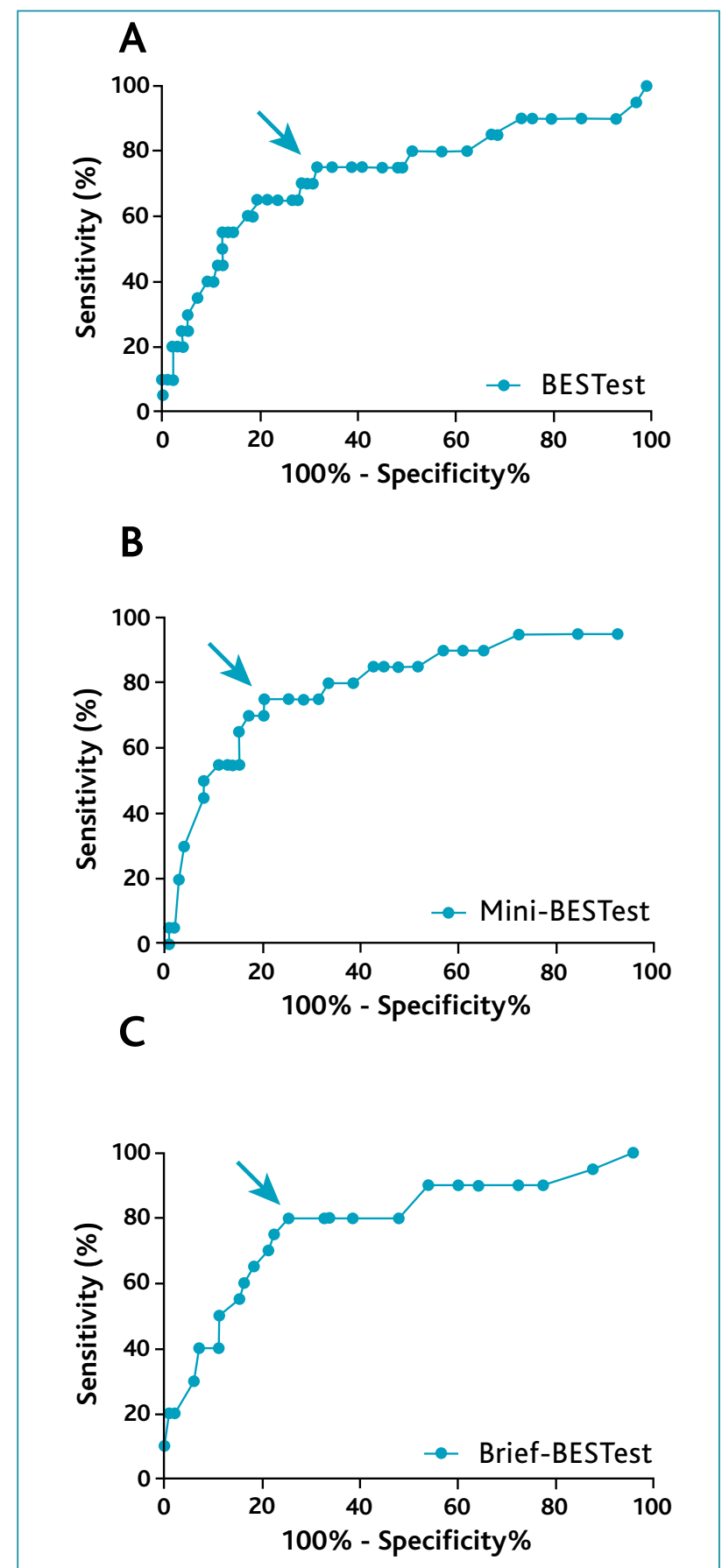

Figure 1. Receiver operator characteristics of the (A) Balance Evaluation Systems Test, (B) Mini-Balance Evaluation System Test and (C) Brief-Balance Evaluation System Test to differentiate between self-reported prior history of non-fallers and multiple fallers. The points corresponding to cutoff points are indicated by arrows $(n=118)$.

Abbreviations: BESTest $=$ Balance Evaluation Systems Test. gait and/or balance impairments, social factors, and quality of life. ${ }^{15}$ These and other risk factors can be easily evaluated with the BESTest and its short versions, ${ }^{14}$ 5STS, 10MWT, BPAAT and WHOQoL-Bref. ${ }^{21,24,29-30}$

The ability of BESTest and its short versions to identify fallers and non-fallers was previously published. ${ }^{14}$ We have found similar results, however, the current study adds information on the ability of these comprehensive balance tools to identify a self-reported prior history of non-fallers and multiple fallers in community-dwelling older people, establishing now specific cutoffs for this purpose which can be especially useful for clinical practice to identify those who are more likely to fall again.

One previous study has determined a cutoff of $12 \mathrm{~s}$ for multiple fallers in the 5STS test. ${ }^{31}$ This result differs slightly from the cutoff of 13.1s established in this study however, our study differentiated non-fallers and multiple fallers based on the self-reported number of falls while that study analyzed falls prospectively and recorded with a monthly calendar. ${ }^{31}$ For the 10MWT, a considerable variance between our cutoff $(1.2 \mathrm{~m} / \mathrm{s})$ and the cutoff proposed in a study including communitydwelling older indigenous Taiwanese $(0.88 \mathrm{~m} / \mathrm{s})$ was found. ${ }^{32}$ However, in the Taiwanese study ${ }^{32}$ only women were included and assessments were taken in a 10 meters corridor with 10 (five+five) meters extra provided for acceleration/deceleration, whilst in our study women and men participated and assessments were taken from a six meters corridor, with four (two+two) meters for acceleration/deceleration, as recommended. ${ }^{24}$ Different methodological approaches might contribute to the different results found between the studies.

A cutoff for falls using a PA tool has been proposed in the literature, ${ }^{33}$ however a different test (short form of the International PA Questionnaire) to assess PA was used, hindering comparisons with the present study. Nevertheless, and similarly to our findings, fallers reported less PA than non-fallers. ${ }^{33}$ Since PA plays an important role in the maintenance of the functional ability independence and decreases the risk of falls, ${ }^{3}$ the established cutoff of 1.5 points for the BPAAT might be useful to quickly screen community-dwelling older people and refer them for a comprehensive balance assessment in case of need. 


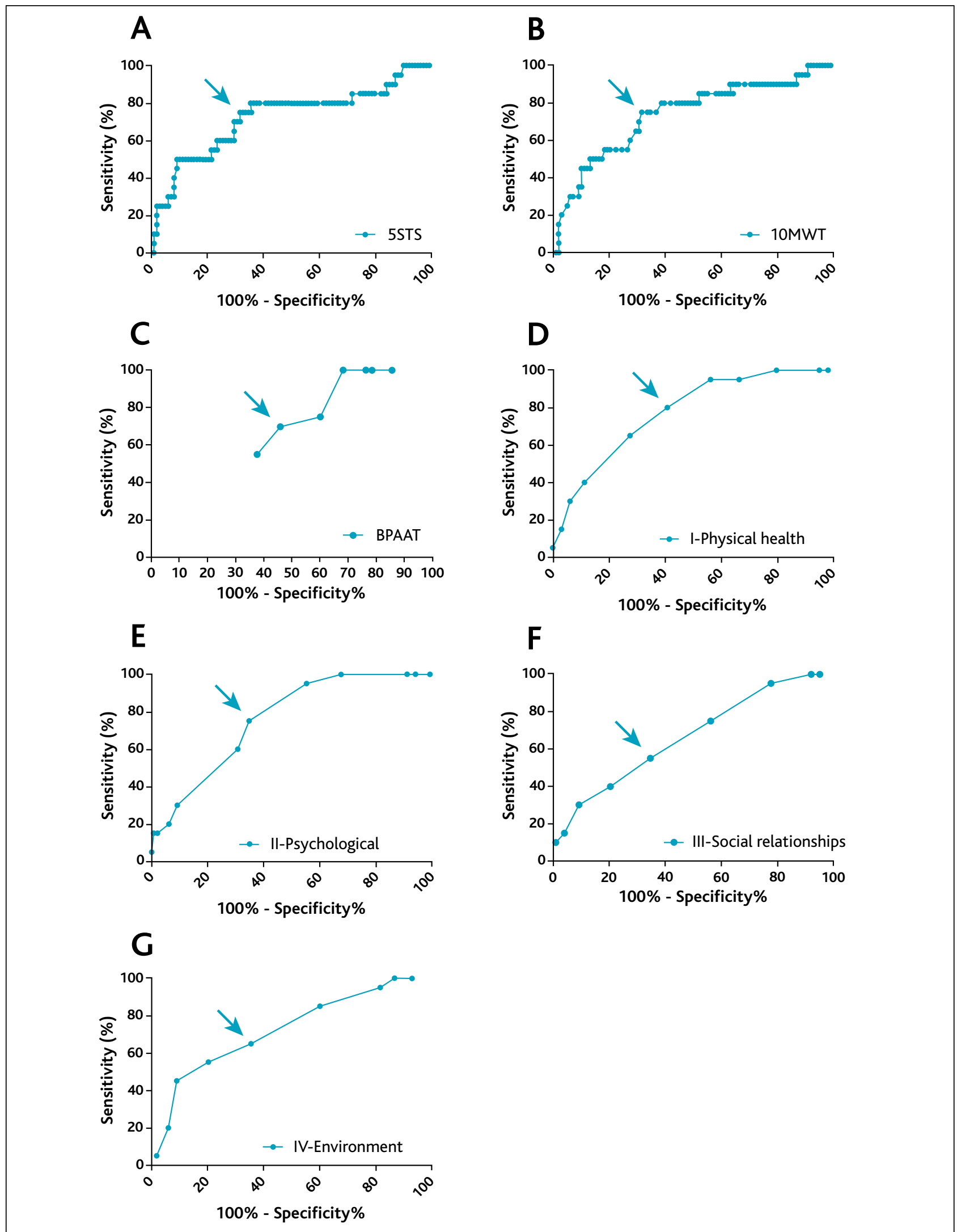

Figure 2. Receiver operator characteristics of the (A) Five Times Sit to Stand Test, (B) 10 Meter Walk Test, (C) Brief Physical Activity Assessment Tool, (D) World Health Organization Quality of Life-Bref Physical health, (E) World Health Organization Quality of Life-Bref Psychological, (F) World Health Organization Quality of Life-Bref Social relationships and (G) World Health Organization Quality of Life-Bref Environment to differentiate between self-reported prior history of non-fallers and multiple fallers. The points corresponding to cutoff points are indicated by arrows $(n=118)$.

Abbreviations: 5 STS $=$ Five Times Sit to Stand Test; 10MWT $=10$ Meter Walk Test; BPAAT $=$ Brief Physical Activity Assessment Tool. 
Our findings showed that multiple-fallers presented worse HRQoL than non-fallers, as corroborated by the literature. ${ }^{8}$ Although the impact of falls on the quality of life is well established, the ability of the quality of life to detect the risk of falls is poorly explored. According to the authors' best knowledge, this is the first study providing a cutoff to distinguish the self-reported prior history of non-fallers and multiple fallers using an HRQoLtool. The established cutoffs for the different domains of the WHOQoL-Bref might be useful to identify those to whom a preventive and/or effective intervention for falls might be a priority.

These values will enable professionals to interpret results with more confidence and take informed action (e.g., referral for comprehensive balance assessments and personalized interventions since those who have fallen are more likely to fall again) ${ }^{22}$ based on the results obtained, preventing disability and promoting healthy aging in community-dwelling older people.

This study has several limitations that need to be acknowledged. Due to the nature of this cross-sectional study, the ability to identify a history of falls was analyzed retrospectively. Thus, future studies should conduct longitudinal studies to assess the ability of the tools to identify multiple fallers prospectively. Moreover, falls were based on individuals' self-report, hence, some degree of bias might have been present despite the important contribution to the understanding balance and functional ability, gait speed, self-reported PA, and HRQoL in community-dwelling older people. MiniBESTest and Brief-BESTest scores were derived from the original BESTest, thus it is possible to have occurred inter-item influences. In future studies, each test should be performed separately.

\section{CONCLUSIONS}

In conclusion, this study showed significant correlations between the BESTest and its short versions, with functional ability, gait speed, self-reported PA, and HRQoL in community-dwelling older people. Higher associations were found with the short versions. Since these comprehensive balance tools allow the identification of domains where balance is preserved or impaired, their use in clinical practice offers great potential to personalize interventions and effectively promote healthy aging in community-older people.
BESTest and its short-versions and tools commonly used to assess functional ability, gait speed, self-reported PA and HRQoL in community-dwelling older people were able to distinguish between the self-reported prior history of non-fallers and multiple fallers. Cutoff points were identified for BESTest, Mini-BESTest, Brief-BESTest, 5STS, 10MWT, BPAAT, and WHOQoLBref. Health professionals can now use these cutoffs to identify those who might benefit from a more comprehensive balance assessment which will inform who to prioritize for balance interventions. These findings are of great importance since falls prevention is a main goal in older populations that needs comprehensive and realistic interventions to be implemented.

\section{REFERENCES}

1. World Health Organization. Ageing and life course [homepage]. Geneva:WHO; 2018. Available from: https://www.who.int/ageing/en/

2. Almeida SI, Marques A, Santos J. Normative values of the balance evaluation system test (BESTest), mini-bestest, brief-bestest, timed up and go test and usual gait speed in healthy older Portuguese people. Rev Port Med Geral Fam. 2017;33(2):106-16.

3. World Health Organization. WHO global report on falls prevention in older age. Geneva:WHO; 2007. ISBN 9789241563536

4. Boyé ND, Van Lieshout EM, Van Beeck EF, Hartholt KA, Van der Cammen TJ, Patka P. The impact of falls in the elderly. Trauma. 2013;15(1):2935.

5. Nilsagård Y, Andreasson M, Carling A, Vesterlin H. Examining the validity and sensitivity to change of the 5 and 10 sit to stand tests in people with multiple sclerosis. Physiother Res Int. 2017;22(4).

6. Spagnuolo DL, Jürgensen SP, Iwama AM, Dourado VZ. Walking for the assessment of balance in healthy subjects older than 40 years. Gerontology. 2010;56(5):467-73.

7. Washburn RA, Smith KW, Jette AM, Janney CA. The physical activity scale for the elderly (PASE): development and evaluation. J Clin Epidemiol. 1993;46(2):153-62.

8. Ozcan A, Donat H, Gelecek N, Ozdirenc M, Karadibak D. The relationship between risk factors for falling and the quality of life in older adults. BMC Public Health. 2005;5:90.

9. Langley FA, Mackintosh SF. Functional balance assessment of older community dwelling adults: a systematic review of the literature. Internet J Allied Health Sci Pract. 2007;5(4):ID13.

10. Santos GM, Souza AC, Virtuoso JF, Tavares GM, Mazo GZ. Predictive values at risk of falling in physically active and no active elderly with berg balance scale. Rev Bras Fisioter. 2011;15(2):95-101.

11. Franchignoni F, Horak F, Godi M, Nardone A, Giordano A. Using psychometric techniques to improve the balance evaluation systems test: the mini-BESTest. J Rehabil Med. 2010;42(4):323-31.

12. Horak FB, Wrisley DM, Frank J. The Balance Evaluation Systems Test (BESTest) to differentiate balance deficits. Phys Ther. 2009;89(5):48498. 
13. Padgett PK, Jacobs JV, Kasser SL. Is the BESTest at its best? A suggested brief version based on interrater reliability, validity, internal consistency, and theoretical construct. Phys Ther. 2012;92(9):1197-207.

14. Marques A, Almeida S, Carvalho J, Cruz J, Oliveira A, Jácome C. Reliability, validity, and ability to identify fall status of the Balance Evaluation Systems Test, Mini-Balance Evaluation Systems Test, and Brief-Balance Evaluation Systems Test in older people living in the community. Arch Phys Med Rehabil. 2016;97(12):2166-73.

15. Deandrea S, Lucenteforte E, Bravi F, Foschi R, La Vecchia C, Negri E. Risk factors for falls in community-dwelling older people: a systematic review and meta-analysis. Epidemiology. 2010;21(5):658-68.

16. Huang TT,Wang WS. Comparison of three established measures of fear of falling in community-dwelling older adults: psychometric testing. Int J Nurs Stud. 2009;46(10):1313-9.

17. Marques A, Cruz J, Quina S, Regêncio $M$, Jácome C. Reliability, agreement and minimal detectable change of the Timed Up \& Go and the 10 Meter Walk tests in older patients with COPD. COPD. 2016;13(3): 279-87.

18. Beauchet O, Annweiler C, Allali G, Berrut G, Herrmann FR, Dubost V. Recurrent falls and dual task-related decrease in walking speed: is there a relationship? J Am Geriatr Soc. 2008;56(7):1265-9.

19. Buatois S, Miljkovic D, Manckoundia P, Gueguen R, Miget $P$, Vançon $G$, et al. Five times sit to stand test is a predictor of recurrent falls in healthy community living subjects aged 65 and older. J Am Geriatr Soc. 2008; 56(8):1575-7.

20. Hwang HF, Liang WM, Chiu YN, Lin MR. Suitability of the WHOQOLBREF for community-dwelling older people in Taiwan. Age Ageing. 2003; 32(6):593-600.

21. Daskalopoulou C, Stubbs B, Kralj C, Koukounari A, Prince M, Prina AM. Physical activity and healthy ageing: a systematic review and metaanalysis of longitudinal cohort studies. Ageing Res Rev. 2017;38:6-17.

22. Ganz DA, BaoY, Shekelle PG, Rubenstein LZ. Will my patient fall? JAMA. 2007;297(1):77-86.

23. United Nations. World population ageing 2019: highlights. New York: UN; 2019. ISBN 9789210045537

24. Bohannon RW. Comfortable and maximum walking speed of adults aged 20-79 years: reference values and determinants. Age Ageing. 1997;26(1):15-9.

25. Marshall A, Smith B, Bauman A, Kaur S, Bull F. Reliability and validity of a brief physical activity assessment for use by family doctors. $\mathrm{Br}$ J Sports Med. 2005;39(5):294-7.

26. World Health Organization. WHOQOL-BREF: introduction, administration, scoring and generic version of the assessment [Internet]. Gene-
va:WHO; 1996. Available from: https://www.who.int/mental_health/ media/en/76.pdf?ua=1

27. Cruz J, Jácome C, Marques A. Validity of the Brief physical activity assessment tool for clinical use in COPD. Eur Respir J. 2017;50(Suppl 61):PA2565.

28. Book review: Three books on statistical power analysis and related ideas. J Stat Comput Simul. 2005;75(12):1019-20.

29. de Labra C, Maseda A, Lorenzo-López L, López-López R, Buján A, Rodríguez-Villamil JL, et al. Social factors and quality of life aspects on frailty syndrome in community-dwelling older adults: the VERISAÚDE study. BMC Geriatr. 2018;18(1):66.

30. Makizako H, Shimada H, Doi T, Tsutsumimoto K, Nakakubo S, Hotta R, et al. Predictive cutoff values of the Five-Times Sit-to-Stand Test and the Timed 'Up \& Go' Test for disability incidence in older people dwelling in the community. Phys Ther. 2017;97(4):417-24.

31. Tiedemann A, Shimada H, Sherrington C, Murray S, Lord S. The comparative ability of eight functional mobility tests for predicting falls in community-dwelling older people. Age Ageing. 2008;37(4):430-5.

32. Chen JC, Liang CC, Chang QX. Comparison of fallers and nonfallers on four physical performance tests: a prospective cohort study of community-dwelling older indigenous Taiwanese women. Int J Gerontol. 2018;12(1):22-6.

33. Pereira CL, Baptista F, Infante P. Role of physical activity in the occurrence of falls and fall-related injuries in community-dwelling adults over 50 years old. Disabil Rehabil. 2014;36(2):117-24.

\section{CONFLICTS OF INTEREST AND SOURCE OF FUNDING}

The authors have no conflict of interest to disclosure.

This work was funded by Programa Operacional de Competitividade e Internacionalização - POCl, through Fundo Europeu de Desenvolvimento Regional - FEDER (POCI-01-0145-FEDER-007628), Fundação para a Ciência e a Tecnologia (PTDC/SAU-SER/28806/2017; SFRH/BD/1206958/2016; SFRH/BD/148741/2019) and under iBiMED - Institute of Biomedicine (UIDB/04501/2020).

\section{CORRESPONDING AUTHOR}

Alda Marques

E-mail: amarques@ua.pt

https://orcid.org/0000-0003-4980-6200

Recebido em 13-11-2019

Aceite para publicação em 07-05-2020 


\section{ABSTRACT}

\section{BALANCE AND HEALTHY AGING: A CLOSE RELATIONSHIP}

Objectives: This study explored the: i) correlations between the Balance Evaluation Systems Test (BESTest) and its short-versions (Mini-BESTest and Brief-BESTest), with functional ability, gait speed, physical activity, and health-related quality of life; ii) ability of the Five Times Sit to Stand (5STS), 10 Meter Walk Test (10MWT), Brief Physical Activity Assessment Tool (BPAAT) and World Health Organization Quality of Life-Bref (WHOQoL-Bref) to identify the prior history of falls in community-dwelling older people.

Methods: An exploratory cross-sectional study was conducted with healthy older people living in the community. Balance (BESTest and its short versions), functional ability (5STS), gait speed (10MWT), physical activity (BPAAT), and health-related quality of life (WHOQoL-Bref) were assessed. Spearman correlation coefficient and receiver operating characteristics analysis were calculated.

Results: One hundred and eighteen individuals (76[69-83.3] years; $n=79,66.9 \%$ female) participated in this study. Correlations between balance and functional ability $(-0.61<r<-0.51, p<0.001)$, gait speed $(0.69<r<0.78, p<0.001)$, physical activity $(0.39$ $<r<0.42, p<0.001)$ and health-related quality of life $(0.28<r<0.57, p \leq 0.002)$ were identified. The following cutoff points to differentiate between prior history of falls were established: 80.5 points for the BESTest, 16.5 points for the Mini-BESTest and 12.5 points for the Brief-BESTest, $13.5 \mathrm{~s}$ for the $5 \mathrm{STS}, 1.2 \mathrm{~m} / \mathrm{s}$ for the $10 \mathrm{MWT}, 1.5$ points for the BPAAT and 14.5/66; 14.5/66; 14/62.5; 15.5/72 points for domains I, II, III and IV, respectively, of the WHOQoL-Bref 0-20/100.

Conclusion: The BESTest and its short versions correlated with functional ability, gait speed, physical activity, and health-related quality of life in older people. These outcomes can differentiate prior history of falls in community-dwelling older people.

Keywords: Community-dwelling older people; Falls; Functional ability; Health-related quality of life; Self-reported physical activity. 


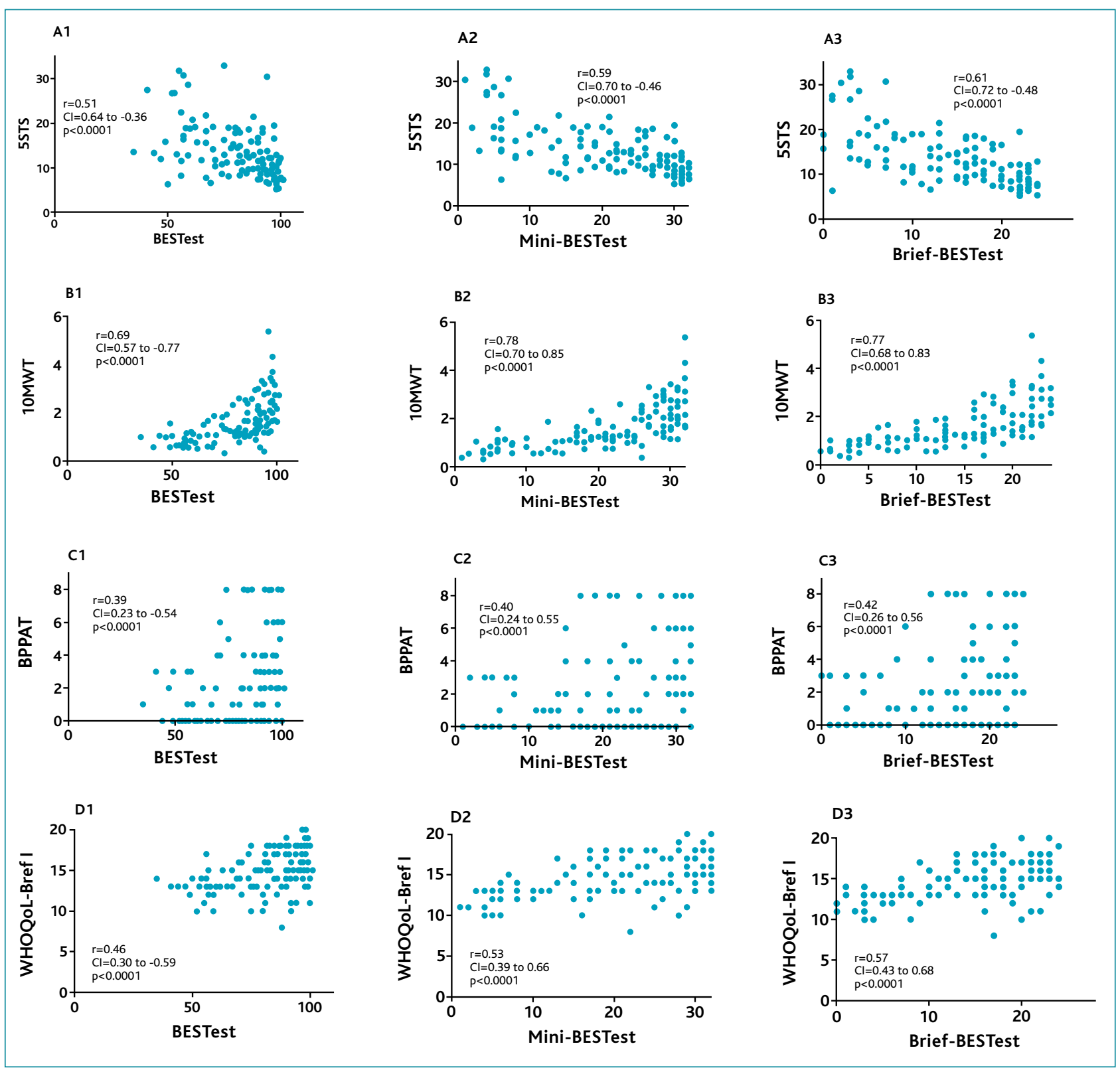

Figure S1. Scatterplots showing the correlations between Balance Evaluation Systems Test, Mini-Balance Evaluation System Test and Brief-Balance Evaluation Systems Test and Five Times Sit to Stand test: A1-3, 10 Meter Walk Test: B1-3, Brief Physical Activity Assessment Tool: C1-3, and World Health Organization Quality of Life-Bref domain I: D1-3, domain II: E1-3, domain III: F1-3, domain IV: G1-3 ( $n=118$ ). Legends: 5STS = Five Times Sit to Stand test; 10MWT = 10 Meter Walk Test; BESTest = Balance Evaluation Systems Test; BPAAT = Brief Physical Activity Assessment Tool; $\mathrm{Cl}=$ Confidence interval; WHOQoL-Bref $=$ World Health Organization Quality of Life-Bref. 

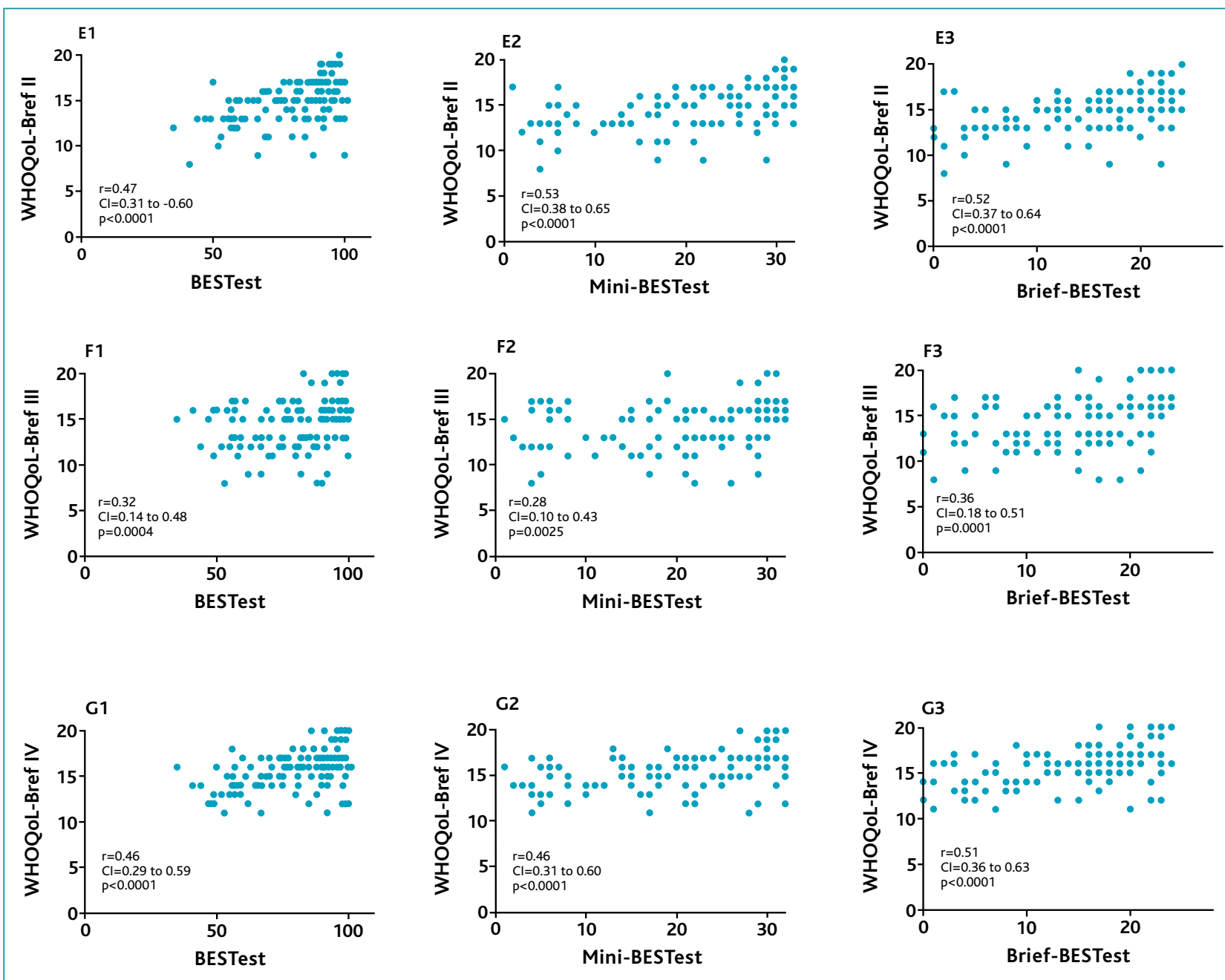

Figure S1. (continuação). 